\section{A COURSE OF}

\section{LECTURES ON SURGERY,} DELIVIRED IN TEM

MEDICAL SCHOOL OF CAMBRIDGE.

By GEORGE MURRAY HUMPHRY, Esa., Downing College, Sprgeon to Addenbrooke's Hospital.

\section{Lecture XXVIII.-Tumours Continued.}

Pancreatic Sarcoma;-Enchondroma; characters of enchondromatous tumours ; the parts most frequently affected by them; they are lobulated or even; their elasticity likely to lead to mistakes as to their nature and connections; they may ossify, undergo calcareous or fatty degeneration, or soften; they are occasionally found in the parotid and mammary glands, and in the testicle;-osseous tumours; their structure; parts affected by them; their tendency to spread along the surface of bones.

IN his classification of tumours, Mr. Abernethy gave the name "pancreatic sarcoma" to one species which he describes as consisting of irregularly-shaped masses, in colour, texture, and size, resembling the larger masses which compose the pancreas. He gives a case of the removal of a tumour of this kind from beneath the lower jaw. Mr. Lawrence has met with instances of the same disease situated in the angle beneath the lower jaw and the ear. The following case, which was under my care seven years ago, serves well to illustrate this variety of tumour :-A woman, aged 50 , in tolerably good health, presented herself at the hospital with a tumour as large as her head projecting from the side of the head and neck: it overhung the zygoma and covered the side of the neck nearly to the clavicle, extending forwards to within an inch and half of the month, and backwards to the hinder margin of the sterno-mastoid muscle; the lobe of the ear and the outer part of the external auditory canal being spread out over it. It was hillocky on the surface, elastic, and vibrating on percussion, as though it contained fluid : at the lower part it felt firm and solid. The integuments and platysma myoides were quite free upon its surface, having accommodated themselves to the great stretching to which they had gradually been subjected. There was no paralysis of the face, although the facial nerve passing over the tumour must have been considerably elongated. The tumour had been growing for twenty years, and was distressing, chiefly on account of its weight. It was evident that its connections were deep, because the external jugular vein passed over its surface; and you know that this veiu runs into the substance of the parotid gland to receive the internal maxillary and temporal veins; any tumour, therefore, in this situation, bearing the external jugular vein upon its surface, must be placed beneath the lower edge of the parotid gland, and in contact with the great vessels Still it appeared that the tumour could be easily moved upon the parts lying under its deeper surface; and it was clear that it did not press upon the pharynx. The operation was, therefore, determined on and performed without much difficulty; the facial nerve being divided and the external carotid artery exposed for a considerable space. The wound healed quickly, and the patient recovered, without any bad symptom: she is still well, and has partially regained the motor power over the muscles of the face. Here is the tumour. You see it contains a great cavity in its interior, caused by the softening of its central part into a dirty turbid fluid, in which some detached half-dissolved masses were floating about. The cavity has no proper lining, but irregularly-shaped, partially separated fragments of the tumour hang into it, and give it a ragged shreddy appearance. The external solid part of the tumour consists of a firm structure, of pale yellow colour, something like a potato or a parsnip : it is not so tough as fibrous tumours generally are; it is more easily torn, breaking off short. It seems to be composed of several small masses closely compressed together. There was a thick laminated capsule removed with it; this capsule was very closely connected with the substance of the tumour. The characters and history were those of a simple tumour, and the result of the operation has been in accordance with that view.

Although Mr. Abernethy says that tumours of this species are found in the substance of the mammary gland, it appears, from the observations of other surgeons, that they occur most frequently, if not exclusively, near the angle of the lower jaw. In some instances they seem to have formed in the substance of the parotid gland; in others the parotid gland has been destroyed by the pressure of the mass growing on its exterior or beneath it. No doubt the characters of these tumours are determined by those of the structures in or near which they grow; and it is not unlikely that the parotid gland itself may be their nidus, standing in the same relation to them that the uterus does to fibrous tumours of that organ. The tumours of this kind are now, by the best pathologists, included in the genus of fibrous tumours: how far their real structure is in accordance with this classification I cannot tell.

The name "enchondroma," given by Muller, and adopted by other pathologists, is applied to a species of tumour which in structure resembles fortal cartilage in many respects. It has the same pale, semitransparent, glassy, or gelatinous aspect as fœtal cartilage, and is seen under the microscope to consist of groups of cells, dispersed in the midst of a clear hyaline substance; this substance exhibits in some cases a fibrous structure, so as to resemble the fibro-cartilage of the adult. In the majority of instances enchondromatous tumours are composed of a number of small masses or lobes, united together by intervening fibrous tissue, and they present a corresponding fissured or lobulated exterior; sometimes they are ball-like, even on the surface, and their sections exhibit a uniform smooth mass of cartilage. In some cases they have a granular aspect, the individual grains being small, and adhering to one another without any inter- 
vening fibrous or areolar tissue. The colour is usually pale; it may afford the indication of vascularity by a slight pink hue. They are invested, more particularly those of the lobulated variety, with tense, shining, closely-adhering fibrous or tendinous envelopes, which seem to form integral parts of the tumours, and which send processes into them, intersecting them, and separating the lobules from one another. Enchondromatous tumours are most common in young persons ; they grow on the exterior of the bones,-on the phalanges, the ribs, and the sternum more especially,-commencing at one point, and creeping along the surface of the bone, so as in course of time to encircle it, and by their pressure they cause its absorption. They appear to spring from the substance of the bone rather than from the periosteum; indeed it is no unusual thing for them to commence in the interior of the bone, and, as they increase, the wall of the bone becomes either absorbed or expanded over them. Those which originate in the interior of the bones are for the most part less lobulated, and present less of the fibrous element in their composition than those which begin under the periosteum. In this specimen the head of the metacarpal bone, and the phalanges of a finger are, with the exception of the articular extremities, and the terminal phalanx, quite destroyed and replaced by cartilaginous tumours, of globular shape, composed of coarse closely-set grains of soft semi-transparent cartilage. Some of them are larger than a walnut; they are not lobulated, the only channels on their surfaces being these deep ones for the flexor tendons. You see the shafts of the phalanges are completely gone, the cartilaginous masses which replace them being the only uniting medium between the articular ends. The finger from which they are taken was removed from a lad, aged 11, who had tumours of a similar nature on the thumb and other fingers; they were not terder or painful, except during changes of weather; and the skin, though much stretched, was unadherent to them. His parents had first observed them when he was a year old; they had gradually increased in size, those on the fore finger becoming so large as to render the finger useless, and disable the whole hand. The elasticity of the tumours was so great, that it was not easy to determine by the touch that they were all connected with the bones, though I had no doubt of their being so. This lad's hand reminded us of the condition to which the fingers are sometimes brought, in cases of severe long-continued gout, attended with deposit of urate of soda upon the phalanges and metacarpal bones. There is, however, this difference to be remarked, that, whereas in the latter disease the swellings are chiefly observed near the joints, in the case of the lad they were most marked along the shafts of the phalanges, between the joints. It is well to remember this difference, because the cartilaginous tumours do sometimes soften and burst through the skin, when the patient grows older, and continue for a great length of time to discharge a turbid chalky fluid looking very much like that which escapes from the swollen fingers of the gouty subject.
The elasticity of the cartilaginous tumours is very likely to mislead you with regard to their nature and connections. About two years ago a gentleman of our profession called upon me requesting that $\mathrm{I}$ would remove what he thought to be a cyst from the fore pant of the first phalanx of his ring finger. He considered it to be a simple affair, and was quite certain that it had no connection with the bone, for he fancied that it could easily be moved upon the bone, and said that when it first appeared, some years previously, it was still looser than at the time when I saw it. The tumour was of oval shape, its long axis being parallel with the bone; it was smooth on the surface, and had a tense elastic feel. At first I was inclined to acquiesce in the opinion that it was not intimately connected, either with the bone or the tendon, but a more carefuk examination convinced me that it was a cartilaginous tumour, growing from the phalanx, and I feared that the fore part of the bone was destroyed, and that possibly the tumour extended for some distance into its cancellous texture. I told the patient, therefore, that the operation would be a more serious affair, and more uncertain in its results, than he contemplated. However, he was determined that an attempt should be made to excise the tumour, and could not be persuaded that it really had any connection with the bone. Having reflected the skin, and turned aside the tendon, I found that the tumour consisted of cartilage, and was closely connected with nearly the whole fore part of the phalanx ; indeed the anterior surface of the phalanx was destroyed. I sliced off the mass and scooped it out from the cancellous texture of the bone as well I could. Less inflammation followed than might have been anticipated after such rough treatment, and a useful finger was recovered. No return of the disease has, I believe, been experienced, nor has it shown itself in any other part, which is remarkable, because these cartilaginous tumours of the fingers are seldom single; they commonly affect several of the phalanges, and separate grains of the morbid structure may very often be found infiltrated into the cancellous tissue of the bone, at a distance from the chief mass.

These cartilaginous tumours not unfrequently ossify in part or throughout their substance. The process may commence at the centre of the small nodules of which they consist; the several bony nuclei thus formed gradually enlarge, inosculate with one another, and form a branching skeleton of cancellous structure. In some instances osseous fibres and plates shoot into the tumour from the bone on which it rests; and the attached portion of the tumour thus becoming ossified, it is difficult to ascertain the line of demarcation between the tumour and the bone. In a third set of cases the ossification takes place primarily and chiefly in the tendinous closely-adherent capsule which usually forms a constituent part of the tumour. In this way a bony shell may be formed, enclosing the tunour; and the latter ceasing to grow is not uncommonly converted into a powdery cretaceous substance, or it may become ossified, or, lastly, it may undergo a kind of fatty degeneration. It seems that these tumours generally contain a good 
deal of oily and cartby matter, for $I$ have observed that when they have been dried the remnant consists chiefly of a mortar-like, or a greasy, white, powdery substance. This tumour, for instance, connected with the ribs, and taken from a young woman, presented, when recent, the ordinary appearance of enchondroma, but now that it has been dried it looks in great part of its substance as if it were composed of cement. Both the oily and earthy constituents in all probability are increased in those cases where the tumour has ceased to grow-a change corresponding to the fatty and earthy degeneration of other structures.

Softening takes place in cartilaginous tumours even more commonly than in the fibrous. It begins usually, as I told you that ossification sometimes does, at the centre of the component nodules; it soon spreads throngh the substance of the nodules, so that in a short time they are liquetied, and cavities are formed, enclosed by the undestroyed septa which intersect the substance of the tumour. Subsequently, the septa giving way, the cavities are rendered confluent, and large caverns are produced, filled with a turbid fluid, and lined with rough fragments of the nndestroyed circumference of the tumour projecting into them.

Enchondromatous tumours, consisting of nodules of cartilage imbedded in a fibrous matrix, and resembling in many particulars those just described as affecting the bones, are occasionally found in the substance or in the immediate neighbourhood of the parotid gland, the mammary gland, and the testicle. Rokitansky describes them as occurring also in the lungs. The growth of these tumours in such situations strikes one at first as being a remarkable anomaly, and as furnishing an argument against the theory of the nature of simple tumours which.I have propounded to you; but, I think, a little reflection will show that it is neither so strange nor so irreconcilable with what has been said. We have found that in a great number of cases the abnormal growth of a portion of tissue, upon which I have supposed a tumour to depend, has been accompanied with more or less alteration of structure. Thus in a wart, the cuticle, the papillæ, and the substance of the cutis are not only increased in quantity, but they are altered in quality; they lose the fine structure of skin, and become coarse and rough. Moreover cysts in various parts of the body, more particularly in the ovary, have hairs, portions of cutis, bone, and teeth formed upon their walls; and the tumours growing in different parts of the body, in animals more particularly, are subject to the development of bone and to many other changes. It seems quite probable that in like manner the formation of a cartilaginous tumour in a gland, or in the substance of a bone, may depend upon the affected portion of tissue not only receiving an impulse in its growth, but acquiring also an alteration in its structure. On such a point, however, we can only speculate in an uncertain manner, and we must not attach too much importance to any hypothesis respecting a subject of so much difficulty.

An equally remarkable fact is the occasional existence of nodules of cartilage in the midst of canceron tumours; they occur, I believe, only in the encephaloid variety of cancer. Here is the section of a testicle enormously enlarged from soft cancer; the whole structure of the testicle has disappeared, and the mass presents the usual appearance of soft cancer, except that in the middle there is a firm ball, as large as an orange, composed of tough fibrous tissue, with cavities containing a clear jelly-like fluid, and small nodules of cartilage in the intestines between the fibres. This is not separate from the rest of the mass, but united to it in its whole circumference by continuity of tissue. The patient, aged 30, had observed the enlargement of the testicle for about a year; he died a few months after its removal from an extension of the disease to the glands in the loins. In this specimen taken from another part of the body, is also seen, in the midst of an encephaloid tumour, a large firm mass consisting of cartilaginous nodules imbedded in a fibrous matrix; the nodules are of various sizes, and many of them present opaque ossifying nuclei at their centres. $\Lambda t$ the upper part of the specimen the encephaloid substance takes the place of the fibrous structure, the cartilaginous masses being imbedded in, and completely surrounded by it.

Enchondromatous tumours are of an innocent nature, although from their numbers and their size they produce destructive consequences upon the bones with which they are connected. In some instances they cease to grow and become calcified or ossified, in others they attain to enormous dimensions. From the nature of their connection with the bones on which they grow, you will understand that it is generally necessary to remove the latter in order to affect a cure. Before determining to do this you should allow the possibility of a spontaneous cessation of increase to have its fair weight in influencing your decision; you should also remember that other bones are likely to be affected in a similar manner, and must therefore be prepared for an appearance of the disease in some other part; this is more particularly true when the tumours appear in the fingers.

The loose cartilages found in joints and the melonseed-like bodies in burse, are probably of a different nature from the tumours now described. They often present, it is true, a nucleus of ossification, but they are of tougher structure, more resembling fibrocartilage. I have already given you my reasons for thinking that they are of inflammatory origin and are dependent npon certain changes taking place in lymph shed upon the internal surface of the lining membranes of bursal or synovial sacs. They appear, in common with the hard white masses found upon the spleen, liver, and other serous surfaces, to have a power of growth independent of the inflammation which gave them birth, and might, therefore, be distinguished by the name "lymph-tumours;" at any rate they seem to form the connecting link, being inflammatory products and tumours strictly so called.

I show you here a remarkable specimen of " osseous tumour," or "ivory tumour" as it is sometimes called 
affecting the fore part of the skull. It consists of a large mass of peculiarly dense osseous structure, growing from the orbital and fore part of the frontal bone. The centre of the tumour corresponds to this part of the skull, and it has grown from that centre about equally in all directions. It measures thirteen inches in circumference, and projects into the cranial cavity as a round knotty mass, which occupies the place of the anterior cerebral lobes. The orbits are almost filled up by it, and the nasal part of the skull is destroyed. The tumour is not confined exclusively to the frontal bone; it grows also from the great ala of the sphenoid bone on both sides, and from the æethmoid bone. A few delicate laminæ of the latter running up into the substance of the tumour are the only traces of it which remain. In most parts, the tumour overlaps the contiguous bones, having crept along their surfaces and then caused their absorption by its pressure. At one place you may trace the frontal bone for a considerable distance into the substance of the tumour; and you may remark, that where it enters the tumour, it becomes more dense, its diploe is obliterated, it gradually acquires more and more of the characters of the tumour, and at length is blended with it; so that it is not quite easy to determine where the natural structure terminates and the morbid product begins, the one seems, as it were, to be assimilated by the other. In some places nodules of the tumour are seen to have originated in the substance of the bone, and to have pressed their way through the tables of the skull or to have expanded the latter over them; just as we sometimes find, in connection with an enchondromatous tumour, separate grains of cartilage lying in the substance of the adjacent cancellous structure of the bone. The section of this tumour shows some portions of it to have a dense cancellous structure, but it is for the most part quite hard, like ivory.

Here is another specimen of a similar kind. It is the breast-bone of a turkey enveloped almost completely in a hard, heavy, osseous tumour, growing from its surface. The tumour is nodulated on the exterior, with fissures extending to variable depths, dividing it into lobes or masses of considerable size. In some parts it is made up of plates and columns of bone growing at right angles from the surface of the sternum, or rather in the direction of the muscular and other fibres attached to that bone.

The tumours of this species are most common about the bones of the head and face: indeed I am not aware that they affect any other part of the body in man. They grow very slowly, and it is owing to this slow growth that they attain to such great size, and effect the displacement or absorption of such important parts-expanding the bones, pressing out the eyeballs, elongating the nerves, and even, as in the specimen just produced, occupying a large space in the cranial cavity, at the expense of the brain. There is no history attached to that specimen, but there can be little doubt that the growth of the tumour was very slow; probably it was many years in attaining so great a size. A few months ago I saw, in St. George's Hospital, a young woman with a tumour, apparently of the same kind, occupying precisely the same position. It was not so large, but the eye-balls were protruded from their sockets, the nasal bones were displaced or absorbed, and it was supposed to be encroaching on the territory of the brain. It had been forming for a great length of time, and made very slow progress.

Osseous tumours are generally knotty on the exterior ; in their outline resembling closely some of the examples of enchondroma. They are composed of very dense bone, containing irregularly disposed corpuscles, with very few canals for the passage of blood-ressels. In some instances they appear as single globular masses: there is a specimen of such an one growing from the angle of the lower jaw in the College of Surgeons. In other cases they extend for a considerable distance along the surface of the bones with which they are connected, causing great enlargement and deformity, and rendering the bones heavy, hard, and tuberculated; in short, producing a condition somewhat analogous to that of hyperostosis, or the thickening of bones from inflammation. There are specimens in the museum of the College of Surgeons in which both the upper and lower jaw bones are affected in this manner throughout their whole extent. It is obviously of much importance to bear in mind this disposition of the disease to spread along the surface of a bone, because it renders a very complete removal of the part affected an essential requisite for the entire eradication of the malady. Moreover, the disease may spread from one bone to another, uniting them firmly together. Thus the growth commencing in a superior maxillary bone may spread to the palate and sphenoid bones, as well as to the opposite side of the face. Such an extension of the disease might not be easily ascertained during life, and would sadly embarrass an operator who had commenced his incisions with the intention of removing one of the upper jaw bones; even if he succeeded in effecting his object the patient would most probably suffer from the further progress of the disease in the other bones. I have been informed that this cause of failure has been experienced in some other cases where the superior maxillary bone was removed with, as it was thought, a fair prospect of success.

It is stated by some pathologists, whose opinion carries very great weight, that these osseous tumours consist only of enchondromatous tumours which have undergone slow and complete ossification, and that they do not, therefore. deserve a distinctive name and class. I must confess it appears to me that this decision has been made somewhat hastily, under a disposition to generalize a little too freely. Cartilaginous tumours, it is true, do undergo ossification to a certain extent; but $I$ have never been able to find an instance in which dense ivory-like bone, similar to that you have seen in the osseous tumour of the skull, was in process of formation in an enchondroma; neither has there appeared to be a trace of cartilaginous structure in any of the osseous tumours which $I$ have had the opportunity of examining. Possibly the formation of cartilage in these tumours may precede the formation of 
bone in the same manner as it often does in exostosis; but there appears to be no distinct evidence that such is really the case; at any rate the general characters and exceedingly slow growth of osseous tumours in every stage of their progress, are opposed to the probability of their having in the first instance consisted of enchondromatous structure, which has subsequently become ossified.

I have little to say respecting the treatment of osseous tumours. Excision is the only remedy; this must include the bone or part of the bone from which they grow, and I have already explained to you the necessity of taking great care that the whole of the morbid structure, together with a margin of bone in its immediate circumference, be removed.

\section{CASE OF}

\section{STRANGULATED INGUINAL HERNIA.}

By T. F. SMITH, Esq., Evesham.

\section{To the Editor of the Provincial Medical and Surgical} Journal.

Sir,-If the following case of strangulated inguinal hernia, in which the operation was performed in the absence of any external tumour, possesses sufficient interest to merit a place in the Journal, you will oblige me by inserting it.

I am, Sir, your obedient servant,

T. F. SMITH.

Evesham, Nov. 2, 1850.

CAsE.-C. Byrd, of Bretforton, aged 45, a strong and hard-working man, has had scrotal hernia of the right side for sixteen or seventeen years, which he says he has always been able to reduce easily. About six years since be discovered a swelling in the left side, which turned out to be also hernia, and which he likewise could readily return up to the time of his recent attack. He has for a long period worn a double truss constantly.

Oa September the 28th I was called to him and found him suffering from strangulation of the hernia on the left side. He stated that he was moving straw from a thrashing machine, when he was suddenly seized with pain in the bowels, accompanied with sickness, and on examination, found that, in consequence of the spring of the truss having got weak the hernia had descended, and he could by no means return it. I saw him three hours after the attack, and instantly put him into a hot bath, tried the taxis, gave him enemata, and. in fact tried the ordinary means for the reduction of the hernia, büt without success. I then gave him ten grains of calomel and one of acetate of morphia, and left him. On visiting him again in the evening I found the tumour had entirely disappeared, the urgent symptoms of strangulated hernia had also subsided. In abont an hour afterwards, however, they all returned with aggravated violence; the pains in the abdomen were excruciating; he began to vomit large quantities of stercoraceous matter, of highly foetid odour; in short, he had all the symptoms found in such cases. I immediately sent for my friend Mr. Beadles, of Broadway, and on his arrival, after a careful examination, we came to the conclusion that there must be a small portion of gut still strangulated at the internal ring. I therefore, by the advice of Mr. Beadles, proceeded to cut into and explore the inguinal canal. The parts were divided as for oblique inguinal hernia, and a knuckle of intestine, of the size of a small nut, was found protruding through, and tightly strangulated by, the internal ring. After cutting through the stricture with a blunt-pointed bistoury, the gut was carefully replaced, and the parts brought together in the usual manner. In a few hours the violent symptoms had altogether disappeared, the wound healed by adhesion, and my patient is now quite recovered.

\section{CYSTICERCUS CELLULOSUS.}

\section{By AUGUSTIN PRICHARD, Esq., Bristor.}

\section{To the Editor of the Provincial Medical and Surgical Journal.}

SIR,-The following case has lately been under my care at the "Dispensary for the Cure of Complaints in the Eyes," in this city, and appears to me to be worthy of being briefly recorded.

I remain, Sir, your obedient Servant, AUGUSTIN PRICHARD.

Bristol, Nov. 6, 1850.

Surgeon.

CASE.-Emily Collins, a healthy young woman, 22 Jears of age, admitted March 20th, 1850, complaining of a small rounded tumour in the inner cantius of the right eye. It was about the size of a pea, and situated anteriorly to the lacrymal sac, and of course superficial to it. It was moreable, slipping readily backwards out of reach into the orbit, but was retained without difficulty in its place by pressing the finger nail behind it. She observed it two or three years ago, and noticed that it became larger in the spring.

As it did not appear to be of sufficient importance to require immediate surgical interference, some stimulating ointment was given to her for daily use, and she was directed to apply again if it increased in size. In a few months she became very anxious for its removal, on acount of the deformity which she. fancied it occasioned.

Faving observed, from the blue and semi-transparent appearance of thenittle swelling, that it contained clear fluid, I determined to remove it entire, to prevent the chance of recurrence, and to preserve it for careful examination; I therefore made a small vertical incision over it, intending to dissect it out; but after the second touch with the knife a clear vesicle presented itself, and gradually escaped from the opening. It was somewhat 